\title{
Assessment of phosphorus availability in soil cultivated with ruzigrass
}

\author{
Danilo S. Almeida ${ }^{\mathrm{a}, *}$, Chad J. Penn ${ }^{\mathrm{b}}$, Ciro A. Rosolem ${ }^{\mathrm{a}}$ \\ a Department of Crop Science, College of Agricultural Sciences, São Paulo State University, 1780 José Barbosa de Barros St., 18610-307 Botucatu, São Paulo, Brazil \\ ${ }^{\mathrm{b}}$ National Soil Erosion Research Laboratory, United States Department of Agriculture, 275 S. Russell St., 47907 West Lafayette, IN, United States
}

\section{A R T I C L E I N F O}

Handling Editor: Junhong Bai

Keywords:

Urochloa ruziziensis

Isothermal titration calorimetry

Phosphorus pools

Organic phosphorus

\begin{abstract}
A B S T R A C T
Growing ruzigrass (Urochloa ruziziensis) in crop rotation systems has been suggested as a strategy to increase soil phosphorus (P) cycling and P availability. However, despite increased P lability shown in routine soil analysis, decreased grain yields of crops grown after ruzigrass have been observed. The objective of this study was to evaluate soil P availability to maize (Zea mays) in low or high-P soil cropped to ruzigrass. Soil P lability was evaluated using Hedley fractionation and pearl resin extractions, and $\mathrm{P}$ desorption/adsorption was assessed by isothermal titration calorimetry (ITC). Phosphorus changes in soil-P fractions in the maize rhizosphere were studied in a greenhouse experiment. Growing ruzigrass resulted in higher resin-extractable $\mathrm{P}$ and soil organic matter (SOM) contents than fallow. However, in soil cropped with ruzigrass, maize P uptake and P desorption were lower, and $\mathrm{P}$ adsorption to soil was higher than soil under fallow. In general, organic $\mathrm{P}$ bound to $\mathrm{Fe}$ and $\mathrm{Al}$ was non-available. Phosphorus sorption as assessed with ITC was a better indicator of P bioavailability to maize than pearl resin and Hedley fractionation, and suggested that $\mathrm{P}$ was less bioavailable after ruzigrass due to increased SOM, which resulted in the formation of metal phytate and more effective organo-metal sites for ligand exchange. Greater P solubility and availability in fallowed soil appeared to be partly due to the dissolution of Carelated $\mathrm{P}$, greater $\mathrm{P}$ desorption, and less potential for $\mathrm{P}$ adsorption. Isothermal titration calorimetry is a useful semi-quantitative tool for understanding $\mathrm{P}$ sorption behavior.
\end{abstract}

\section{Introduction}

Species of the genus Urochloa have been largely adopted in cropping system rotations in Brazil. Ruzigrass [Urochloa ruziziensis (R. Germ. and C.M. Evrard) Morrone and Zuloaga] is the most used due to its characteristics as both livestock feed and cover crop in integrated crop-livestock systems. According to Boddey et al. (1996), ruzigrass is well adapted to low soil fertility, low $\mathrm{pH}$, and $\mathrm{Al}$ toxicity in soil, and has high yield, palatability and nutritional quality for animal feed. Ruzigrass is also tolerant to low $\mathrm{P}$ availability due to a high $\mathrm{P}$ uptake efficiency, and has been studied in crop system rotations intended to increase soil $\mathrm{P}$ availability through P cycling (Merlin et al., 2013; Almeida, 2014; Almeida and Rosolem, 2016).

The high P uptake efficiency by ruzigrass may be related to an extensive root system (Boddey et al., 1996) and the ability of roots to exude low-molecular weight organic acids (LMWOAs), such as citrate (Wenzl et al., 2001), that give access to Fe- and Al-bound P (Merlin et al., 2015). Almeida and Rosolem (2016) observed an increase in water-extractable $\mathrm{P}$, labile $\mathrm{P}$, and moderately labile $\mathrm{P}$ forms in upper soil layers, and a decrease in recalcitrant $\mathrm{P}$ in subsurface soil layers as a result of ruzigrass cultivation during the soybean [Glycine max (L.)
Merrill] off-season. Hence, P cycling may be increased in systems where ruzigrass is introduced (Merlin et al., 2013; Almeida, 2014; Almeida and Rosolem, 2016). However, Almeida (2014) observed lower leaf P concentration and lower soybean grain yield after growing ruzigrass than in soil kept fallow. Since soybean leaf P concentration was lower after ruzigrass (Almeida, 2014), it was hypothesized that growing ruzigrass reduces soil $\mathrm{P}$ availability to subsequent crops partly due to a decrease in $\mathrm{P}$ desorption from the soil cultivated with ruzigrass. There is also the hypothesis that $\mathrm{P}$ extracted by resin and soil $\mathrm{P}$ fractionation are not able to truly estimate $\mathrm{P}$ availability to plants grown in rotation with ruzigrass.

Phosphorus is predominantly retained in soil through ligand exchange by 1:1 clay minerals, $\mathrm{Fe}$ and $\mathrm{Al}$ oxides and hydroxides, and precipitated as Fe, Al and $\mathrm{Ca}$ phosphates (Sparks, 2003). By understanding the sorption mechanisms, $\mathrm{P}$ management to improve $\mathrm{P}$ use efficiency can be better planned (Sharpley, 1995). Sorption isotherms and $\mathrm{P}$ sorption index are commonly used in soil $\mathrm{P}$ sorption studies (Anghinoni et al., 1996; Campos et al., 2016). However, isotherms and $\mathrm{P}$ sorption index are not suited for the determination of precise sorption reactions (Veith and Sposito, 1977). Isothermal titration calorimetry (ITC) has been used as a complementary technique for establishing $\mathrm{P}$

\footnotetext{
* Corresponding author.

E-mail address: daniloalmeida@fca.unesp.br (D.S. Almeida).
} 
sorption reactions, providing a sensitive and direct quantitative measure of heat in a reaction (Penn and Warren, 2009; Penn and Zhang, 2010; Lyngsie et al., 2014). Penn and Warren (2009) studied P adsorption by kaolinite using ITC, and observed that reactions of P adsorption by ligand change resulted in exothermic reactions, whereas phosphate precipitation with $\mathrm{Al}$ resulted in endothermic reactions. The same authors observed that $\mathrm{NaH}_{2} \mathrm{PO}_{4}$ titration in $\mathrm{AlCl}_{3}$ and $\mathrm{FeCl}_{3}$ solutions resulted in an endothermic reaction, because of $\mathrm{P}$ precipitation with $\mathrm{Al}$ and $\mathrm{Fe}$. Titration of $\mathrm{HCl}$ to kaolinite was exothermic due to mineral dissolution. Another exothermic reaction was the adsorption of fluoride to kaolinite. These observations were confirmed with soils of mixed mineralogy, displaying exothermic reactions with ligand exchange to variable charged minerals (Penn and Zhang, 2010; Penn et al., 2014). Moreover, it was found that precipitation of Ca phosphate was exothermic (Penn and Zhang, 2010).

The objectives of this study were to directly measure the amounts and forms of soil $\mathrm{P}$ available to maize plants in soil previously cultivated with ruzigrass at two different soil $\mathrm{P}$ levels, and evaluate $\mathrm{P}$ sorption-desorption using ITC in the context of relative P uptake and soil $\mathrm{P}$ availability.

\section{Materials and methods}

Soil samples were collected from a long-term experiment in Botucatu, Brazil ( $22^{\circ} 50^{\prime} 00^{\prime \prime} \mathrm{S} ; 48^{\circ} 25^{\prime} 31^{\prime \prime} \mathrm{W}$; at altitude $806 \mathrm{~m}$ ), cropped under no-till since 1998. The area selected for the long-term experiment had not been cropped for several years before 1998. From 1998 to 2005 , no-till soybean was grown in the summer in rotation with black oat (Avena strigosa Schreb.) or triticale (x Triticosecale Witt.) in the fallwinter, and pearl millet [Pennisetum glaucum (L.) R. Br.] in the spring. Since 2006, soybean has been grown in rotation with ruzigrass or fallow. The soil is a well-drained Rhodic Hapludox (Soil Survey Staff, 2014 ) with $67 \%$ of sand and $21 \%$ of clay. Selected chemical characteristics of the soil are presented in Table 1.

Soil samples were taken from plots with different $\mathrm{P}$ fertilization and crop rotation for soil analysis and for a greenhouse experiment. Treatments comprised the combination of the following long-term fertilizer applications and cropping systems: low-P soil samples taken from plots not fertilized with P since 1998, and high-P soil that has received a total of $427 \mathrm{~kg} \mathrm{ha}^{-1}$ of P applied as triple superphosphate (TSP) from 1998 to 2012; and presence or absence of ruzigrass grown as a cover crop during the off-season. Soil samples were taken from depths of $0-5$ and $0-20 \mathrm{~cm}$ in November 2012, after ruzigrass desiccation. Six soil subsamples were randomly taken from the $0-5 \mathrm{~cm}$ depth of each plot using a $50 \mathrm{~mm}$ diameter core sampler and composited. Three soil subsamples were collected from the $0-20 \mathrm{~cm}$ depth of each plot using a shovel to obtain a sufficient amount to perform a greenhouse experiment.

Subsamples from both depths were air-dried and passed through a 2-mm sieve for subsequent chemical analysis of available P (Resin-P)

Table 1

Selected chemical characteristics of the soil at different depths before the long-term experiment was planted in 1998

\begin{tabular}{lllllllll}
\hline \multirow{2}{*}{ Depth } & $\mathrm{pH}^{\mathrm{a}}$ & $\mathrm{SOM}^{\mathrm{b}}$ & $\mathrm{Resin}^{\mathrm{C}} \mathrm{C}^{\mathrm{n}}$ & $\mathrm{H}+\mathrm{Al}^{\mathrm{d}}$ & $\mathrm{K}$ & $\mathrm{Ca}$ & $\mathrm{Mg}$ & $\mathrm{CEC}^{\mathrm{e}}$ \\
\cline { 3 - 8 } $\mathrm{cm}$ & & $\mathrm{g} \mathrm{kg}^{-1}$ & $\mathrm{mg} \mathrm{kg}^{-1}$ & \multicolumn{5}{c}{$\mathrm{mmol}_{\mathrm{c}} \mathrm{kg}^{-1}$} \\
\hline $0-5$ & 5.2 & 21 & 18 & 27 & 2.7 & 21 & 13 & 64 \\
$5-10$ & 5.1 & 18 & 16 & 28 & 0.7 & 17 & 11 & 57 \\
$10-20$ & 4.6 & 19 & 5 & 34 & 0.6 & 8 & 6 & 48 \\
\hline
\end{tabular}

${ }^{\text {a }}$ Soil $\mathrm{pH}$ measured in calcium chloride solution.

b Soil organic matter.

c Phosphorus extracted with pearl resin. According to Raij et al. (1986).

d Potential acidity.

e Cation exchange capacity. and Ca extracted with pearl resin (Raij et al., 1986), $\mathrm{pH}$ in $0.01 \mathrm{~mol} \mathrm{~L}^{-1}$ $\mathrm{CaCl}_{2}$, SOM, and potential acidity $(\mathrm{H}+\mathrm{Al})$, as described in Raij et al. (2001). Soil P fractionation was conducted based on a modification of the Hedley fractionation (Hedley et al., 1982) as proposed by Condron and Goh (1989). Briefly, $0.5 \mathrm{~g}$ soil samples were placed in centrifuge tubes and subjected to the following extraction sequence: anion exchange resin (AER) type AR-204SZRA (GE Water \& Process Technologies, Pennsylvania, U.S.); $0.5 \mathrm{~mol} \mathrm{~L}^{-1}$ sodium bicarbonate $\left(\mathrm{NaHCO}_{3}\right)$ pH 8.5; $0.1 \mathrm{~mol} \mathrm{~L}^{-1}$ sodium hydroxide $(0.1-\mathrm{NaOH}) ; 0.1 \mathrm{~mol} \mathrm{~L}^{-1}$ hydrochloric acid $(\mathrm{HCl})$; and $0.5 \mathrm{~mol} \mathrm{~L}^{-1} \mathrm{NaOH}$ sodium hydroxide $(0.5$ $\mathrm{NaOH}$ ). After extraction, the soil was dried in an oven at $50{ }^{\circ} \mathrm{C}$, ground in an agate mortar, and $0.1 \mathrm{~g}$ of the soil was subjected to nitric-perchloric digestion for the extraction of residual P (Residual-P). A standard spike ( $500 \mathrm{mg} \mathrm{kg}^{-1}$ of P) was added to few soil samples to assess recovery efficiency of the nitric-perchloric digestion, which was in average $92 \%$, approximately. The acid extracts obtained with AER, $\mathrm{HCl}$, and nitric-perchloric digestion were used to determine inorganic $\mathrm{P}\left(\mathrm{P}_{\mathrm{i}}\right)$ concentrations using the molybdate blue and ascorbic acid method (Murphy and Riley, 1962). The alkaline extracts obtained with $\mathrm{NaHCO}_{3}$ and $\mathrm{NaOH}$ were divided into two aliquots. In the first aliquot of each extract, the concentration of $P_{i}$ was determined immediately after extraction to prevent the hydrolysis of organic $\mathrm{P}\left(\mathrm{P}_{\mathrm{o}}\right)$ present in the extract (Dick and Tabatabai, 1977). Accordingly, the following $P_{i}$ fractions were obtained: $\mathrm{NaHCO}_{3}-\mathrm{P}_{\mathrm{i}}, 0.1-\mathrm{NaOH}-\mathrm{P}_{\mathrm{i}}$, and $0.5-\mathrm{NaOH}-\mathrm{P}_{\mathrm{i}}$. The second aliquot was subjected to digestion with ammonium persulfate $\left[\left(\mathrm{NH}_{4}\right)_{2} \mathrm{~S}_{2} \mathrm{O}_{8}\right]$ and sulfuric acid $\left(\mathrm{H}_{2} \mathrm{SO}_{4}\right)$ in an autoclave to determine the total $\mathrm{P}\left(\mathrm{P}_{\mathrm{t}}\right)$ content of each extract. The difference between the $\mathrm{P}_{t}$ and $P_{i}$ was assumed to equal $P_{o}$ for each extract. Thus, the following extracted $\mathrm{P}$ fractions were obtained: $\mathrm{NaHCO}_{3}-\mathrm{P}_{\mathrm{t}}, \mathrm{NaHCO}_{3}-\mathrm{P}_{\mathrm{o}}, 0.1-$ $\mathrm{NaOH}-\mathrm{P}_{\mathrm{t}}, 0.1-\mathrm{NaOH}-\mathrm{P}_{\mathrm{o}}, 0.5-\mathrm{NaOH}-\mathrm{P}_{\mathrm{t}}$, and 0.5-NaOH- $\mathrm{P}_{\mathrm{o}}$. All fractionation analyses were done in triplicate. The $\mathrm{P}$ concentration was determined using a spectrophotometer (Model 600S, FEMTO, Brazil). The sum of all extracted $P$ fractions from fractionation analysis was labeled as Total-P, including Residual-P. Comparison of total P measured directly with summed $\mathrm{P}$ fractions revealed that the fractionation recovered an average $80 \%$ of total P.

\subsection{Isothermal titration calorimetry}

Samples collected from the $0-5 \mathrm{~cm}$ depth were subjected to tests of soil $\mathrm{P}$ desorption and adsorption by isotherm titration calorimetry (ITC), model CSC 4200 (CSC Inc., Utah, U.S.) at $25^{\circ} \mathrm{C}$. Since no-till results in more pronounced effects on $\mathrm{P}$ availability in the uppermost soil layers, the $0-5 \mathrm{~cm}$ layer was chosen. Soils were titrated with $\mathrm{P}$ to obtain a semi-quantitative indicator of the ability to sorb $\mathrm{P}$ along with some indicator of $\mathrm{P}$ sorption mechanisms. In addition, titration and extraction with citric acid was chosen to investigate potential $\mathrm{P}$ desorption because citric acid is excreted by plant roots to increase $\mathrm{P}$ bioavailability in the rhizosphere (Jones and Darrah, 1994; Hinsinger, 2001).

The ITC has a sensitivity of $0.418 \mu \mathrm{J}$ detectable heat effect and a "noise level" of $\pm 0.0418 \mu \mathrm{J}$ (deconvoluted signal). All samples were analyzed with 25 titrations of $0.01 \mathrm{~mL}$ of titrant in $300 \mathrm{~s}$ intervals. For each experiment, a blank was determined by titration of the respective solution into deionized (DI) water, and subtracted from the measurements of the samples. For the ITC analysis, $50 \mathrm{mg}$ of soil sample was placed in a $1.3 \mathrm{~mL}$ ampule filled with $0.75 \mathrm{~mL}$ of distilled water and titrated with the appropriate solution. Quality and Assurance (Q \& A) procedures involved applying a precise sweep of electrical inputs into the ITC prior to measuring samples, for the purpose of instrument calibration via measurement of ampoule heat coeficients. In addition, two different types of check samples were utilized as part of Q \& A. Due to the fact that temperature is highly controlled to prevent heating or cooling, drift is $<100 \mu^{\circ} \mathrm{C}$ over $24 \mathrm{~h}$, making the analysis highly repeatable (Penn and Warren, 2009). For P sorption, a solution of $0.01 \mathrm{~mol} \mathrm{~L}^{-1} \mathrm{NaH}_{2} \mathrm{PO}_{4}$ was used as the titrant, according to Penn and 
Warren (2009). To estimate the heat of P desorption/dissolution, samples of each treatment were titrated with $0.001 \mathrm{~mol} \mathrm{~L}^{-1}$ citric acid ( $\mathrm{pH}$ 5.5). The heat rates measured by ITC were plotted with time to produce a thermogram, and the heat rate from each titration was integrated to produce a heat curve. In addition, a complementary benchtop citric acid extraction was conducted to simulate the ITC analysis using the same soil:solution ratio and equilibration time. For the benchtop analysis, $1 \mathrm{~g}$ of soil sample was placed in a $50 \mathrm{~mL}$ falcon tube filled with $15 \mathrm{~mL}$ of distilled water and titrated with $0.001 \mathrm{~mol} \mathrm{~L}^{-1}$ citric acid ( $\mathrm{pH} 5.5$ ), adding $0.2 \mathrm{~mL}$ of titrant in $300 \mathrm{~s}$ intervals. The equilibrated solutions were centrifuged at $3000 \times g$ for $10 \mathrm{~min}$, filtered through $0.45 \mu \mathrm{M}$ membranes, and analyzed for $\mathrm{P}, \mathrm{Ca}$, $\mathrm{Al}$, and Fe by inductively coupled plasma atomic emission spectroscopy (ICP-AES). More information about termal response of citrate addition to soils and solutions can be found in the supplementary material.

\subsection{Greenhouse experiment}

In the greenhouse experiment, maize was used as a direct measurement of the ruzigrass effect on soil $\mathrm{P}$ bioavailability. Maize was chosen over soybean because maize is generally considered to be more responsive to $\mathrm{P}$ than soybean. A greenhouse experiment was opted for this study instead of a field experiment to allow for precise rhizosphere soil sampling. Maize was grown in 6-litre pots filled with $7 \mathrm{~kg}$ of soil taken from the field experiment. For this experiment, the soil collected from the $0-20 \mathrm{~cm}$ depth in the field experiment was air-dried and passed through a 4-mm sieve to separate roots, rocks and debris. Five maize seeds were sown in each pot and two plants were maintained after emergence. At 35 days after emergence, the plants were harvested, roots were separated from shoots, and any soil adhered to the roots was gently separated and analyzed (rhizosphere soil). Phosphorus extraction with resin (Resin-P) was performed on bulk soil from pre-maize and rhizosphere soil, as in Raij et al. (1986). Phosphorus fractionation was also performed as previously described, and the change in P concentration $(\Delta \mathrm{P})$ between soil sampled before maize growth and rhizosphere soil sample was calculated. The change in $\mathrm{P}$ concentration for each fraction was calculated as: $\Delta \mathrm{P}=$ soil $\mathrm{P}$ concentration before maize growth - soil P concentration in rhizosphere after maize growth.

After rhizosphere soil sampling, the roots were washed and stored in a $50 \%$ ethanol solution at $5{ }^{\circ} \mathrm{C}$. Root length and average diameter were digitalized using a scanner with $300 \mathrm{dpi}$ resolution, and analyzed using the WhinRhizo software (version 3.8-b, Regent Instrument Inc., Quebec, Canada). Following analysis, root and shoot samples were dried to a constant mass in an air-forced oven $\left(65^{\circ} \mathrm{C}\right)$ to measure dry mass, then ground and sieved through a $1 \mathrm{~mm}$ screen to measure $P$ concentration and P uptake as described in Malavolta et al. (1997).

\subsection{Statistics}

All soil analyses data from the field and P fractionation, as well as plant and soil analyses from the greenhouse experiment, were subjected to analysis of variance (ANOVA), following a $2 \times 2$ factorial in randomized complete block design, with four replications. The GLM procedure in SAS software (version 9.4, SAS Inst., North Carolina, U.S.) was used for these analyses, and means were compared by Tukey's multi comparison test $(p<0.05)$. Results from the ITC were plotted as heat rates with time. For each titration period, the heat rate was also integrated in order to produce a thermogram, which is a plot of heat produced (or consumed) vs. titration number. The heat produced vs. titration number data was adjusted to a logarithmic equation using SigmaPlot software (version 11, Systat Software Inc., California, U.S.).
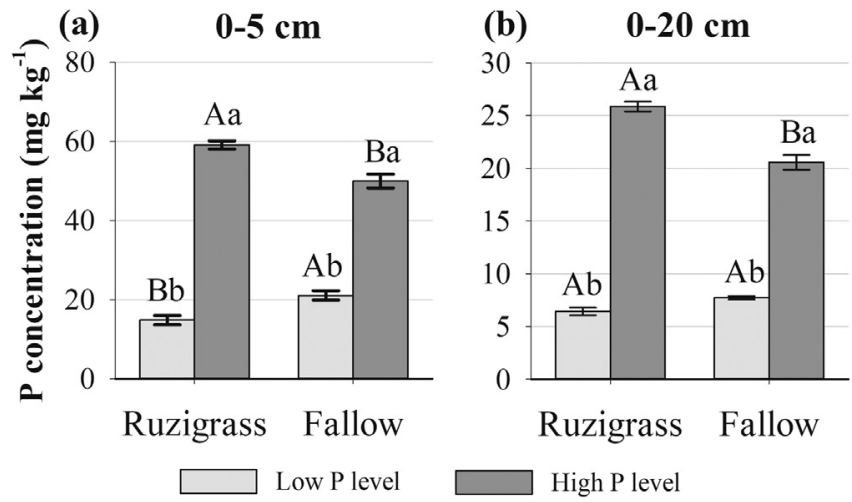

Fig. 1. Soil $\mathrm{P}$ concentration extracted by resin (Resin-P) in $0-5 \mathrm{~cm}$ (a) and $0-20 \mathrm{~cm}$ (b) soil layers, as a function of ruzigrass cultivation and soil P level. Means followed by the same letter were not significantly different (Tukey's Range Test, $p<0.05$ ). Uppercase letters compare soil cultivated to ruzigrass and soil left in fallow, and lowercase letters compare soil P levels. Error bars represent the standard error.

\section{Results}

\subsection{Initial soil analysis}

Resin-P was higher after ruzigrass than fallow for the treatment with high $\mathrm{P}$ level in the $0-5 \mathrm{~cm}$ layer (Fig. 1a). However, for the low-P soil, fallow resulted in higher Resin-P than ruzigrass (Fig. 1a). In the $0-5 \mathrm{~cm}$ soil layer, the SOM was higher after ruzigrass than fallow, 19.6 and $16.0 \mathrm{mg} \mathrm{dm}^{-3}$, respectively. Soil Ca content was higher in soil fertilized with P, 47.5 and $38.8 \mathrm{mmol}_{\mathrm{c}} \mathrm{dm}^{-3}$ in the soil with high and low $\mathrm{P}$ level, respectively. There was no difference in soil $\mathrm{pH}$ and total acidity, which averaged 5.9 and $19.5 \mathrm{mmol}_{\mathrm{C}} \mathrm{dm}^{-3}$, respectively. In soil $\mathrm{P}$ fractionation, there were no interactions of the ruzigrass and soil $\mathrm{P}$ level. Ruzigrass resulted in a higher $\mathrm{P}$ content for several fractions in the $0-5 \mathrm{~cm}$ soil layer in the fallow treatment regardless of the soil $\mathrm{P}$ level (Fig. 2a). Typical labile soil $\mathrm{P}$ fractions (AER-P, $\mathrm{NaHCO}_{3}-\mathrm{P}_{\mathrm{t}}$, $\left.\mathrm{NaHCO}_{3}-\mathrm{P}_{\mathrm{o}}\right)$, moderately labile soil $\mathrm{P}$ fractions $\left(0.1-\mathrm{NaOH}-\mathrm{P}_{\mathrm{t}}\right)$, and low labile fractions $\left(0.5-\mathrm{NaOH}-\mathrm{P}_{\mathrm{i}}\right)$ were higher after ruzigrass than fallow (Fig. 2a). The effect of ruzigrass on the soil $\mathrm{P}$ forms appears to not be related to soil $\mathrm{P}$ level, since there was no interaction between ruzigrass and soil P level. Practically all soil P fractions were higher in the high-P soil except for $0.5-\mathrm{NaOH}-\mathrm{P}_{\mathrm{o}}$, which was not affected by $\mathrm{P}$ fertilizer treatments (Fig. 2b).

Similar results were obtained for initial soil analysis at $0-5 \mathrm{~cm}$ and 0-20 cm depths. Samples collected from ruzigrass plots had higher SOM than fallow soil, which averaged 15.4 and $12.5 \mathrm{mg} \mathrm{dm}^{-3}$, respectively. No differences were observed between ruzigrass and fallow for $\mathrm{pH}$ and potential acidity, with 4.9 and $39.7 \mathrm{mmol}_{\mathrm{c}} \mathrm{dm}^{-3}$ averages, respectively. However, there was an interaction between ruzigrass and soil $\mathrm{P}$ level for Resin-P concentrations. The Resin-P (Fig. 1b) was higher after ruzigrass than in fallow in the high-P soils. Soil Ca content was greater in the high-P soil than low P-soil, which averaged 19.4 and $20.7 \mathrm{mmol}_{\mathrm{c}} \mathrm{dm}^{-3}$, respectively.

\section{2. $P$ desorption with citric acid}

Titration with citric acid was initially exothermic with each additional titration becoming more endothermic. The thermogram for citric acid titrations in low-P soil cultivated with ruzigrass showed a continuous decrease in exothermic reactions, with the final net reactions displaying little heat absorption or release (i.e. near 0) (Fig. 3a), whereas the thermogram from the fallowed low-P soil showed predominant net endothermic peaks (Fig. 3c). The heat curve obtained with citric acid titration in the low-P soil cropped to ruzigrass, remained net negative (i.e. exothermic) for all titrations (Fig. 3b), while the fallow soil with low $\mathrm{P}$ level resulted in net positive values (i.e. 


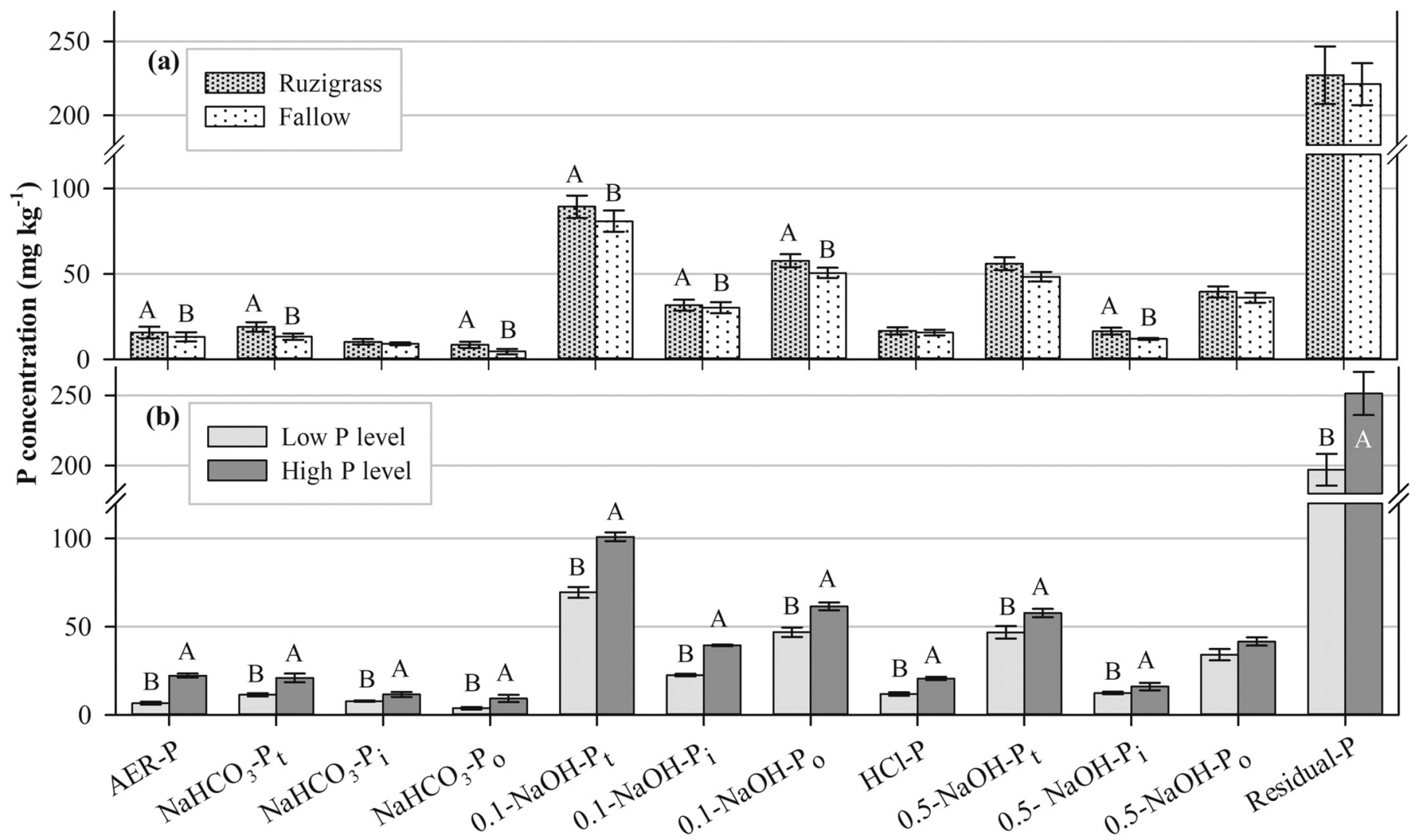

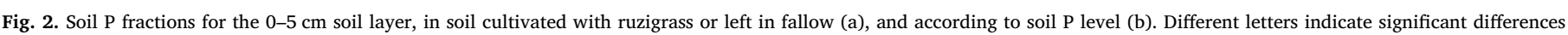
between treatments by Tukey's Range Test $(p<0.05)$, for each soil $\mathrm{P}$ fraction. Error bars represent the standard error.

endothermic) after ten titrations (Fig. 3d). The thermogram for citrate titrations into high-P soil cultivated with ruzigrass mostly displayed exothermic reactions (Fig. 3e) that were net exothermic (Fig. 3f). The fallowed high-P soil initially displayed exothermic reactions that decreased with each titration and began to develop endothermic reactions (Fig. $3 \mathrm{~g}$ ) after ten titrations, and became net endothermic and near zero at titration 23 (Fig. 3h). The complementary citric acid extractions of the low-P soils conducted with the purpose of simulating the ITC experiment showed that ruzigrass soils had a greater amount of $\mathrm{P}$ and $\mathrm{Ca}$ released after 25 titrations compared with fallow (Fig. 4). Extracted Fe and $\mathrm{Al}$ concentrations were similar, while twice as much Ca was released in ruzigrass soils (Fig. 4).

The speciation modelling of the solution titrations clearly followed the same pattern as the thermogram; as free $\mathrm{Al}$ and $\mathrm{Al}$ hydroxide species in solution were consumed by citrate complexation, the endothermic heat response decreased until nearly all solution $\mathrm{Al}$ was complexed (Fig. S1). On the other hand, titration of citric acid into the Al-coated (Fig. S2) and Al-coated $+\mathrm{P}$ treated sand (Fig. S3) was net exothermic with sequential titrations becoming slightly more endothermic, which eventually resulted in the final titrations becoming nearly net zero in heat.

\subsection{P adsorption}

The first titrations with $\mathrm{NaH}_{2} \mathrm{PO}_{4}$ in soil cropped to ruzigrass were highly exothermic, regardless of soil $\mathrm{P}$ level. The first titration in soil cultivated with ruzigrass resulted in a release of $-645 \mu \mathrm{J}$ (Fig. 5b) and $-504 \mu \mathrm{J}$ (Fig. 5f) of heat for the low and high P, respectively. On the other hand, the first titration on fallow soil with low and high P levels, resulted in heat productions of only $-245 \mu \mathrm{J}$ (Fig. $5 \mathrm{~d}$ ) and $-371 \mu \mathrm{J}$ (Fig. 5h), respectively.

Unlike soil cultivated with ruzigrass (Fig. 5a), fallow resulted in smaller exothermic peaks when soil P levels were low (Fig. 5c), compared with high P (Fig. 5g). The net heat measured for soil cultivated with ruzigrass at low $\mathrm{P}$ levels (Fig. 5b) resulted in more net exothermic and less net endothermic titrations than for the low-P fallow soil (Fig. 5d). When ruzigrass was grown in high-P soil (Fig. 5e) fewer differences were observed between fallow and cropped soils than for the low-P soils, although the ruzigrass high-P soil displayed more exothermic reactions upon P titrations compared with fallow (Fig. $5 g$ ).

\subsection{Maize plants analysis}

Growing ruzigrass before maize had no effect on maize dry matter yield. However, low-P soil resulted in less maize root and shoot dry matter compared with the high-P soil (Table 2). Both the root length and the average diameter of maize roots were affected only by soil $\mathrm{P}$ level. The total root length was 307 and $954 \mathrm{~m}$, for soil with low and high P level, respectively. The average diameter of maize roots was 0.26 and $0.23 \mathrm{~mm}$, for soil with low and high P level, respectively. Shoot P concentration was lower in soil cultivated with ruzigrass than under fallow, with averages of 1.95 and $2.72 \mathrm{mg} \mathrm{kg}^{-1}$ of $\mathrm{P}$, respectively. Root $\mathrm{P}$ concentration was not affected by ruzigrass or soil $\mathrm{P}$ level, showing an average value of $0.76 \mathrm{~g} \mathrm{~kg}^{-1}$ of $\mathrm{P}$. There was a main effect of ruzigrass and soil P level on shoot P uptake and total P uptake (shoot plus root $\mathrm{P}$ uptake). The $\mathrm{P}$ uptake in soil cultivated with ruzigrass was lower than after fallow, and also lower in soil with a low P level than in the soil fertilized with phosphates (Table 2).

\subsection{Rhizosphere soil analysis}

The calculated change $(\Delta \mathrm{P})$ in soil $\mathrm{P}$ fractions between samples collected before and after maize cultivation in rhizosphere soil can be interpreted as net plant uptake, or transformation of $\mathrm{P}$ from that pool to another (negative values mean $\mathrm{P}$ is lost to other fractions or taken up by maize). Some interactions of soil $\mathrm{P}$ level and previous cultivation were 


\section{P desorption}

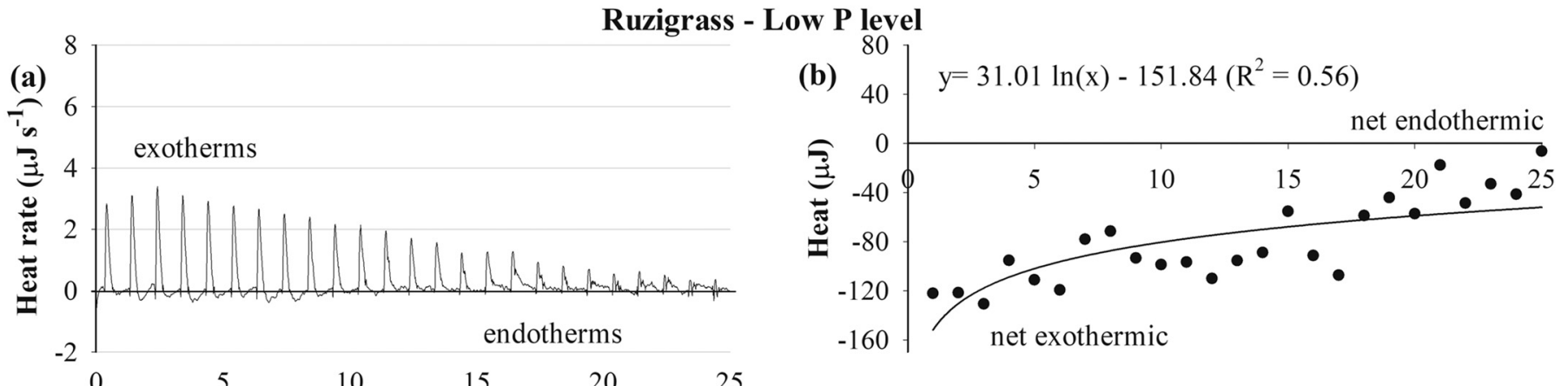

Fallow - Low P level
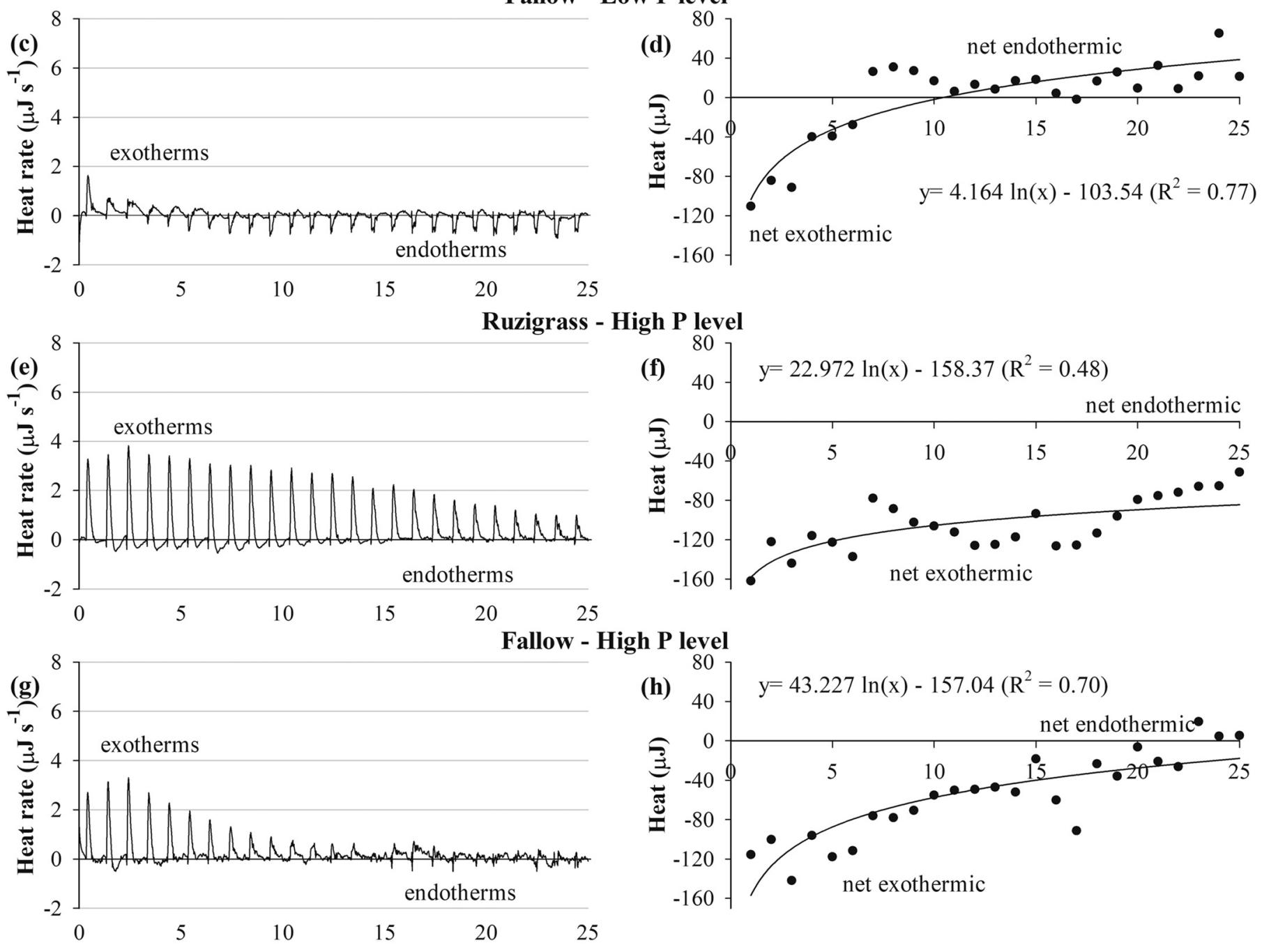

\section{Number of titrations}

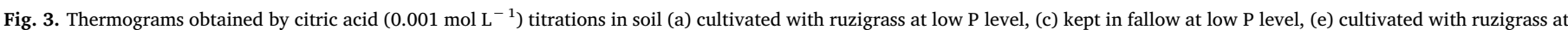
high P level, and $(\mathrm{g})$ kept in fallow at high $\mathrm{P}$ level. Heat curves produced by integration of the thermograms are shown to right of each thermogram in b, $\mathrm{d}$, $\mathrm{f}$, and h.

observed (Fig. 6). There was a lower decrease in the AER-P in soil cultivated with ruzigrass than in fallow soil with a high $\mathrm{P}$ level, while in the low-P soil, there was a higher decrease in AER-P in soil cultivated with ruzigrass than in fallow soil (Fig. 6a). Total soil P concentrations extracted with $0.1-\mathrm{NaOH}$ increased in the rhizosphere only when ruzigrass was previously cultivated on the high-P soil (Fig. 6b). Rhizosphere $\mathrm{P}_{\mathrm{o}}$ extracted with $0.1-\mathrm{NaOH}$ increased in all treatments, but mostly for the high-P soil cultivated with ruzigrass (Fig. 6c).
For some other $\mathrm{P}$ fractions, there were no interactions (Fig. 7). Regardless of previous cultivation, the amounts of $\mathrm{P}_{t}$ and $\mathrm{P}_{\mathrm{o}}$ extracted with $\mathrm{NaHCO}_{3}$ were greater in rhizosphere post-harvest samples than in soil sampled before maize growth (Fig. 7a). However, either less P was taken up or higher amounts of soil $\mathrm{P}$ were transformed into $\mathrm{NaHCO}_{3}-\mathrm{P}_{\mathrm{t}}$ and $\mathrm{NaHCO}_{3}-\mathrm{P}_{\mathrm{o}}$ in the rhizosphere in soils cultivated with ruzigrass compared with fallow (Fig. 7a). Ruzigrass soil also resulted in either less $\mathrm{P}$ uptake by maize or greater transformation of $\mathrm{P}$ into the labile 

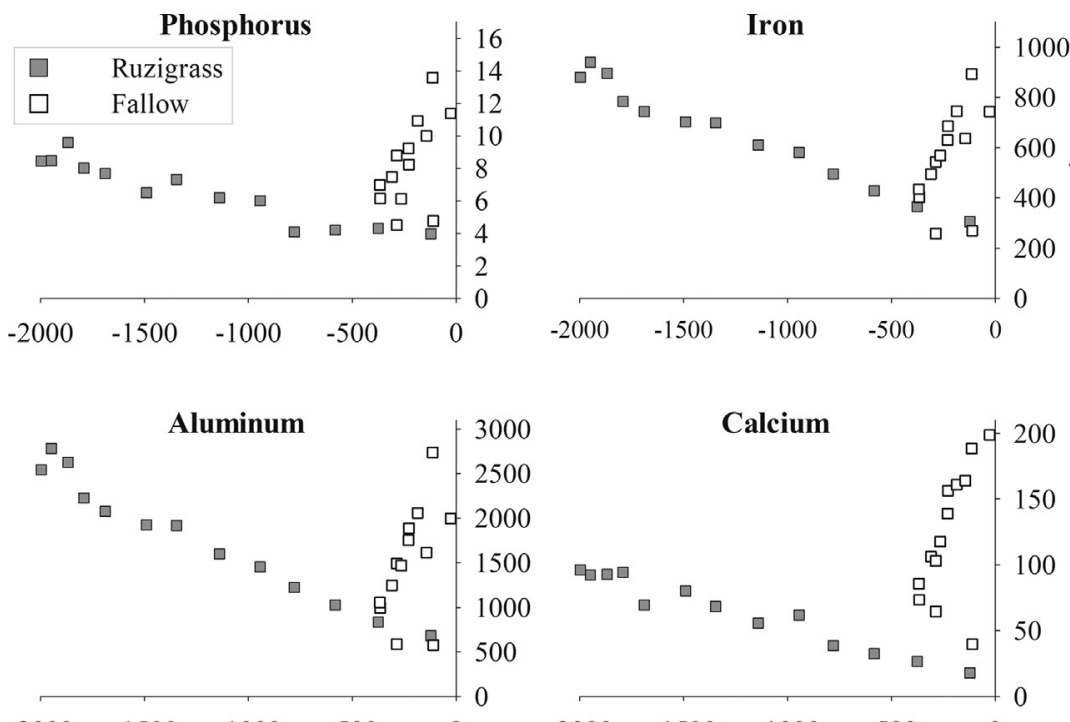

$-2000-1500-1000 \quad-500 \quad 0$

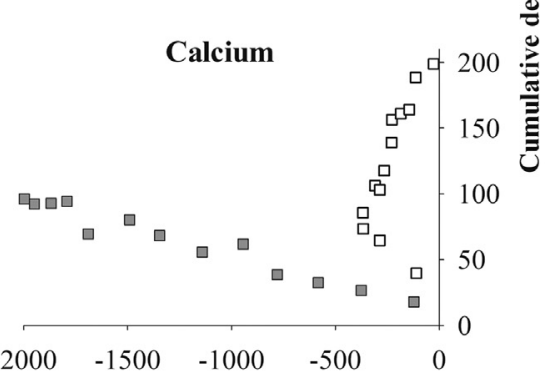

Fig. 4. Cumulative $\mathrm{P}, \mathrm{Fe}, \mathrm{Al}$, and $\mathrm{Ca}$ desorption/dissolution versus cumulative heat $(\mu \mathrm{J})$, from titration with $0.001 \mathrm{~mol} \mathrm{~L}^{-1}$ of citrate (Fig. 5) in soil cultivated with ruzigrass or left in fallow, with low $\mathrm{P}$ level.

Cumulative heat $(\mu J)$

pool (sum of AER and $\mathrm{NaHCO}_{3}$-extractable P) compared with fallow (Fig. 7a).

The $\mathrm{P}_{\mathrm{i}}$ fractions extracted with $\mathrm{NaHCO}_{3}$ and $0.5-\mathrm{NaOH}$ had a higher uptake by maize, or were transformed into different $\mathrm{P}$ pools in soil cropped to ruzigrass than in fallow soil (Fig. 7a). Regarding potential differences between soils with different P levels, 0.1-NaOH- $\mathrm{P}_{\mathrm{i}}$, HCl-P, and Residual-P were either more bioavailable to maize or were transformed from these pools into different fractions, for soil with high background P levels than in plots with low P levels (Fig. 7b). The sum of all fractions, including Residual-P (Total-P), decreased in the maize rhizosphere for both soil $\mathrm{P}$ levels, but growing ruzigrass had no significant effect. Since the Total-P was obtained by calculation, and $\mathrm{P}$ fractionation is a method that could result in cumulative errors, the variation reduces the likelihood of statistically significant differences in Total-P. There was no effect of treatments on $\mathrm{P}_{\mathrm{t}}$ and $\mathrm{P}_{\mathrm{o}}$ extracted with $0.5-\mathrm{NaOH}$, with averages of 19.7 and $15.1 \mathrm{mg} \mathrm{kg}^{-1}$, respectively.

\section{Discussion}

\subsection{Total phosphorus uptake by maize and indicators of labile $P$}

Increases in labile $\mathrm{P}$ forms, as observed in soil $\mathrm{P}$ extracted by pearl resin and fractionation analysis, have been associated with increased SOM (Almeida et al., 2003). According to Pavinato and Rosolem (2008), increases in SOM and the likely exudation of LMWOAs by ruzigrass, may result in a higher labile soil $\mathrm{P}$ content. As shown in $\mathrm{P}$ fractionation results, ruzigrass also increased the $0.1-\mathrm{NaOH}$-extractable $\mathrm{P}$ pool (Fig. 2a). Although the $\mathrm{P}$ fraction extracted by $0.1-\mathrm{NaOH}$ has been interpreted as $\mathrm{P}$ associated with $\mathrm{Fe}$ and $\mathrm{Al}$ (Cross and Schlesinger, 1995), some authors have found this $P$ fraction to be important to plant nutrition, mainly in highly weathered soils, since this fraction acts as a buffer for AER and $\mathrm{NaHCO}_{3}$-extractable $\mathrm{P}$ (Olibone and Rosolem, 2010). However, as observed in a field experiment with soybean grown after ruzigrass (Almeida, 2014), poor P nutrition of maize was observed in the present study, which is an indication that this impact on $\mathrm{P}$ availability is not relegated to only soybean plants. In this case, shoot $\mathrm{P}$ concentration and Total P uptake in maize was approximately $30 \%$ lower when it was grown in soil previously cultivated with ruzigrass than after fallow. These results contrast with the results of the Resin-P and labile $\mathrm{P}$ pools from soil fractionation, which supports the hypothesis that resin extraction is not always indicative of the actual bioavailability of $\mathrm{P}$ in soils previously cropped to ruzigrass. On the other hand, the results of citrate extractions and heat of adsorption and desorption was more related to plant $\mathrm{P}$ uptake. The low $\mathrm{P}$ uptake by maize that resulted in lower shoot $\mathrm{P}$ concentrations in soil cultivated with ruzigrass was not due to poor root development, since no differences were observed in root length and average root diameter. This is significant, since this $\mathrm{P}$ recycled by ruzigrass, although apparently available, is not accessible by plants and is not prone to be lost to the environment.

\subsection{Using ITC as a tool for exploring soil P lability}

Titration of citric acid into an $\mathrm{Al}$ solution for the purpose of creating Al-citrate solution complexes was endothermic, which supports previous measurements made by $\mathrm{Wu}$ et al. (1997). Regardless of the Al concentration of the solution tested, the simulation of the titration experiment with speciation modelling corresponded to endotherms that disappeared after no more Al-citrate complexes were formed (Fig. S1). On the other hand, titration of citrate onto the Al-coated sand material was clearly exothermic (Fig. S2). It is interesting to note that titration of the Al-coated sand with $\mathrm{P}$ displayed a lower degree of exotherms from citrate titration compared with the non-P-treated Al-coated sand (Figs. S2 and S3). This suggests that ligand exchange of citrate onto the variable charged $\mathrm{Al}$ minerals was inhibited by $\mathrm{P}$ that was already occupying the terminal hydroxide sites. For example, Geelhoed et al. (1998) showed that while phosphate and citrate competed in ligand exchange onto soils and a pure iron hydroxide mineral, phosphate was a more effective competitor. Similarly, several studies have found that the binding sites for P and citrate are similar and mostly associated with ligand exchange onto $\mathrm{Al}$ and $\mathrm{Fe}$ oxyhydroxide surfaces (Jones and Kochian, 1996; Jones and Brassington, 1998).

For thermograms and heat curves obtained after titrations with citric acid, contrasting patterns were observed between soils after ruzigrass and fallow. In general, titration with citric acid resulted in initial exotherms that sequentially decreased while endotherms increased. Exotherms often indicate ligand exchange onto variable charged minerals as previously shown for F, DNA, and P (Miltenburg and Golterman, 1997; Rhue et al., 2002; Penn and Warren, 2009). As found in this study, ligand exchange of citrate onto Al-coated sand was also exothermic. Exotherms have also indicated the precipitation of $\mathrm{Ca}$ phosphate and dissolution of $\mathrm{Fe}$ and $\mathrm{Al}$ phosphates, while endotherms can be indicative of dissolution of $\mathrm{Ca}$ phosphate and precipitation of $\mathrm{Al}$ and Fe phosphate (Rhue et al., 2002; Penn and Warren, 2009; Penn and 


\section{$P$ adsorption}
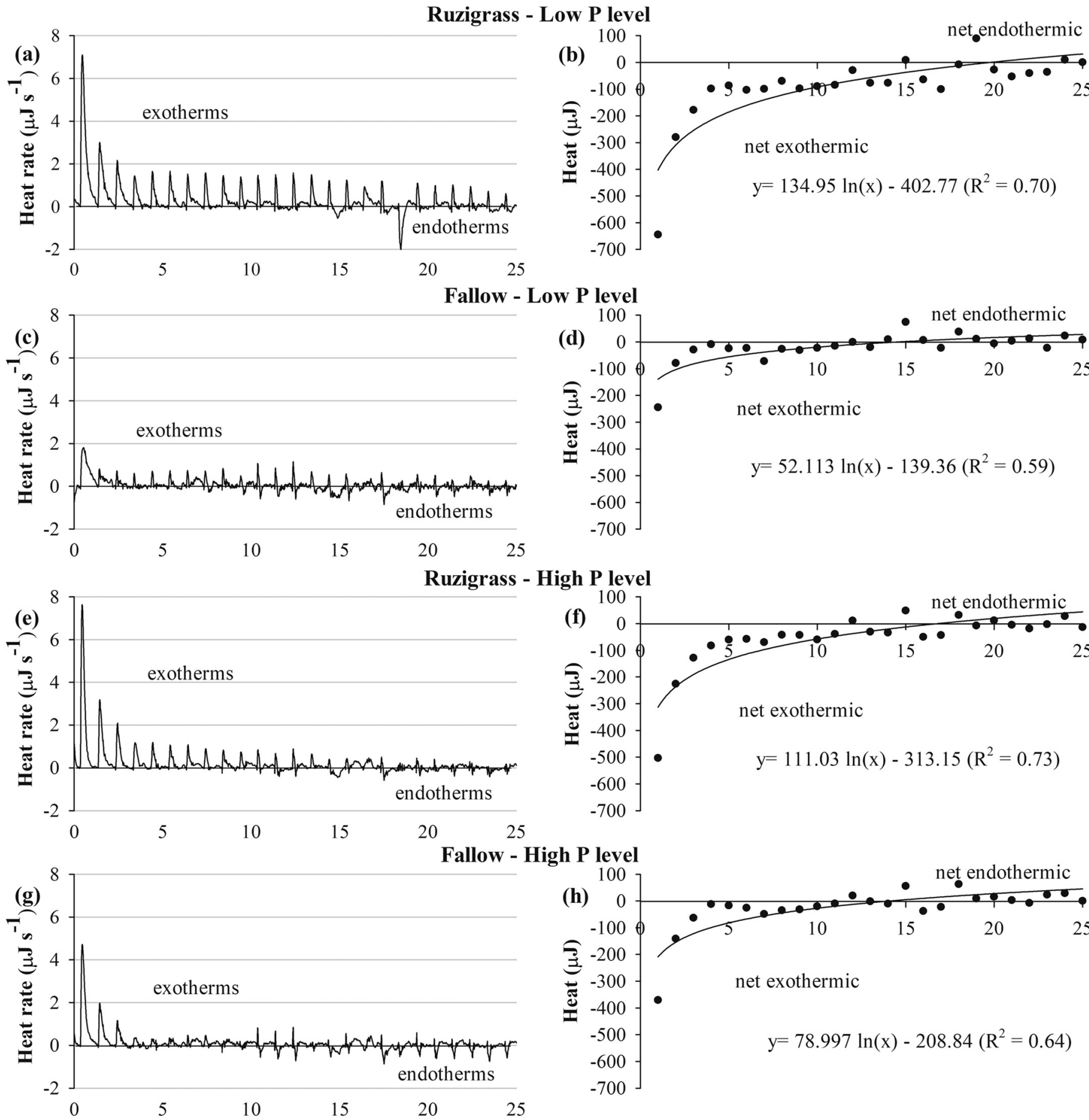

Number of titrations

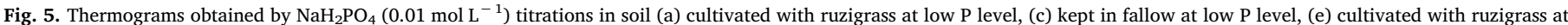
high P level, and (g) kept in fallow at high P level. Heat curves produced by integration of the thermograms are shown to the right of each thermogram in b, d, f, and h.

Zhang, 2010). It is worth mentioning that several of these reactions often occur simultaneously, which is evident from the observation of individual titration peaks in Figs. 3, 5, and S2 and S3.

Coupling the calorimetric measurements from citric acid titrations of the low-P soils with the corresponding solution concentrations, the ruzigrass soil extract has similar amounts of $\mathrm{Al}$ and $\mathrm{Fe}$ as the fallow soil, but more P and Ca was extracted from the fallow soil (Fig. 4). After 25 titrations, there was 8.5 and $13.5 \mathrm{mg} \mathrm{P} \mathrm{kg}^{-1}$, and about 100 and
$200 \mathrm{mg} \mathrm{Ca} \mathrm{kg}{ }^{-1}$ extracted from the ruzigrass and fallow soils, respectively. Again, the differences in $\mathrm{P}$ extracted by citrate agree with the measured maize bioavailability: less $\mathrm{P}$ uptake by maize in soils previously cultivated in ruzigrass. Plotting the heat response of citrate titration against the resulting solution concentrations showed two opposite trends: increasing or decreasing $\mathrm{Fe}, \mathrm{Al}, \mathrm{P}$, and $\mathrm{Ca}$ concentrations with cumulative heat produced (Fig. 4). Again, this is indicative of the different heat response and processes occurring in the ruzigrass 
Table 2

Shoot, root, and total dry weight and $\mathrm{P}$ uptake of maize plants 35 days after emergence, as a function of ruzigrass cultivation and soil P level.

\begin{tabular}{|c|c|c|c|c|}
\hline \multirow[t]{2}{*}{ Soil management } & \multicolumn{2}{|c|}{ Soil P level } & \multirow[t]{2}{*}{ Average } & \multirow[t]{2}{*}{ Standard error } \\
\hline & Low P level & High P level & & \\
\hline \multicolumn{5}{|c|}{ Shoot dry weight $\left(\mathrm{g} \mathrm{pot}^{-1}\right)$} \\
\hline Ruzigrass & 2.3 & 7.5 & $4.9 \mathrm{~ns}$ & 1.0 \\
\hline Fallow & 2.4 & 8.7 & $5.3 \mathrm{~ns}$ & 1.2 \\
\hline Average & $2.3 \mathrm{a}^{\mathrm{a}}$ & $8.1 \mathrm{~b}$ & & \\
\hline Standard error & 0.3 & 0.4 & & \\
\hline \multicolumn{5}{|c|}{ Root dry weight $\left(\mathrm{g} \mathrm{pot}^{-1}\right)$} \\
\hline Ruzigrass & 1.7 & 4.1 & $2.9 \mathrm{~ns}$ & 0.5 \\
\hline Fallow & 1.9 & 4.3 & $3.1 \mathrm{~ns}$ & 0.5 \\
\hline Average & $1.8 \mathrm{a}$ & $4.2 \mathrm{~b}$ & & \\
\hline Standard error & 0.2 & 0.2 & & \\
\hline \multicolumn{5}{|c|}{ Total dry weight $\left(\mathrm{g} \mathrm{pot}^{-1}\right)$} \\
\hline Ruzigrass & 3.8 & 11.4 & $7.6 \mathrm{~ns}$ & 1.5 \\
\hline Fallow & 4.4 & 13.3 & $8.8 \mathrm{~ns}$ & 1.7 \\
\hline Average & $4.1 \mathrm{~b}$ & $12.3 \mathrm{a}$ & & \\
\hline Standard error & 0.5 & 0.5 & & \\
\hline \multicolumn{5}{|c|}{ Shoot P uptake (mg pot $\left.{ }^{-1}\right)$} \\
\hline Ruzigrass & 3.7 & 17.0 & $10.4 \mathrm{~B}$ & 2.8 \\
\hline Fallow & 5.8 & 26.3 & $16.0 \mathrm{~A}$ & 4.1 \\
\hline Average & $4.7 \mathrm{~b}$ & $21.6 \mathrm{a}$ & & \\
\hline Standard error & 0.7 & 2.4 & & \\
\hline \multicolumn{5}{|c|}{ Root P uptake (mg pot ${ }^{-1}$ ) } \\
\hline Ruzigrass & 0.9 & 3.1 & $2.0 \mathrm{~ns}$ & 0.3 \\
\hline Fallow & 1.1 & 5.2 & $3.2 \mathrm{~ns}$ & 0.7 \\
\hline Average & $1.0 \mathrm{a}$ & $4.2 \mathrm{~b}$ & & \\
\hline Standard error & 0.2 & 2.5 & & \\
\hline \multicolumn{5}{|c|}{ Total $\mathrm{P}$ uptake (mg pot ${ }^{-1}$ ) } \\
\hline Ruzigrass & 4.5 & 20.0 & $12.2 \mathrm{~B}$ & 3.1 \\
\hline Fallow & 6.9 & 31.8 & $19.3 \mathrm{~A}$ & 4.8 \\
\hline Average & $5.7 \mathrm{~b}$ & $25.9 \mathrm{a}$ & & \\
\hline Standard error & 0.8 & 2.6 & & \\
\hline
\end{tabular}

ns not significant

${ }^{a}$ Averages followed by different lowercase letter in lines and uppercase in columns are significantly different by Tukey's Range Test $(p<0.05)$.

compared with fallowed soil. For citrate titration of low-P ruzigrass soils, the exotherms appear to be associated with $\mathrm{P}$ release, while the fallow soils mostly exhibited endotherms with P release.

The greater degree of exotherms and endotherms produced by citrate titration of ruzigrass and fallow soils, respectively, suggests that there was more solution $\mathrm{Al}$ (and potentially $\mathrm{Fe}$ ) complexation by citrate in the fallow soils (endothermic), while the ruzigrass soils had more adsorption of citrate to soil surfaces (exothermic). Ruzigrass soils may have had less solution $\mathrm{Al}$ complexation with citrate, due to the presence of organic compounds that already had $\mathrm{Al}$ and $\mathrm{Fe}$ somewhat bound (Berggren and Mulder, 1995). Consider that ligand exchange of citrate onto soil $\mathrm{Al}$ and $\mathrm{Fe}$ oxyhydroxides can displace phosphate into solution (Geelhoed et al., 1998; Jones and Brassington, 1998). Another exothermic reaction that would release $\mathrm{P}$ into solution, and additionally $\mathrm{Al}$ and $\mathrm{Fe}$, is the dissolution of $\mathrm{Al}$ and $\mathrm{Fe}$ phosphates, which can also be promoted through citric acid. The endotherms associated with $P$ release in the fallow soils may have been associated with the dissolution of $\mathrm{Ca}$ phosphates, which is known to be endothermic (Penn and Zhang, 2010). This is plausible since the titration of citrate into the fallow soils released twice as much Ca compared to ruzigrass soil. Due to the acidity of the citric acid solution ( $\mathrm{pH}$ 5.5), it can easily dissolve soil Ca phosphate into solution since Ca phosphate mineral solubility increases with decreasing $\mathrm{pH}$. Organic acids have been shown to increase the release of $\mathrm{P}$ through the dissolution of $\mathrm{Ca}$ phosphates and $\mathrm{Fe}$ and $\mathrm{Al}$ oxyhydroxides that have P bound to them (Earl et al., 1979; Fox et al., 1990).

Both ligand exchange of citrate (which can release P) and dissolution of Ca phosphate and metal oxyhydroxides were likely to be simultaneously occurring in each soil, but because they are opposite in heat response, one reaction can be somewhat "masked" or partly cancelled out by the dominant one regarding heat. This raises the question of why the fallow soil would have more Ca phosphate dissolution, while the ruzigrass soil would have more ligand exchange of citrate. One hypothesis is that since the ruzigrass soil contained more organic matter than the fallow soil (Table 2), it could have provided more surfaces for ligand exchange of citrate without necessarily desorbing the native $\mathrm{P}$ into solution. The lower $\mathrm{P}$ availability determined by titrations with citric acid and resulting measured $\mathrm{P}$ concentrations in soil cultivated with ruzigrass could also be related to $\mathrm{P}_{\mathrm{o}}$ forms, potentially phytate, which has low bioavailability and solubility (Berg and Joern, 2006; Giaveno et al., 2010). Iron and $\mathrm{Al}$ phytate compounds (i.e. phytic acid that react with metal cations to form metal-phytate) particularly lack solubility and lability compared to Ca and Na phytate (Dao, 2003; Dao, 2004; He et al., 2006). In addition, amorphous metal hydroxides can adsorb and protect phytic acid from enzymatic hydrolysis (Dao, 2004). This $P_{o}$ pool is extracted with $\mathrm{NaOH}$ (Warren et al., 2008). Notice that the $0.1-\mathrm{NaOH}-\mathrm{P}_{\mathrm{o}}$ was significantly greater for the soil previously cultivated in ruzigrass than fallow (Fig. 2a). Regarding the Ca phosphate dissolution, although the HCl-P extractable pool from the sequential fractionation analysis suggested that the two soils were not different in Ca phosphate contents, perhaps the impact of ruzigrass cultivation on soil P allowed for a transformation of P into pools not associated with Ca.

Not only did the ruzigrass soils desorb less $\mathrm{P}$, they also had greater potential to adsorb more $\mathrm{P}$ than the fallow soils, which also helps to explain the observation of less maize $P$ uptake by the ruzigrass soil, even though the resin-P extractable concentration was higher. The lower exothermic pattern obtained after titrations with $\mathrm{NaH}_{2} \mathrm{PO}_{4}$ in the fallow soil (Fig. $5 \mathrm{c}$ and $\mathrm{g}$ ) indicates a lower $\mathrm{P}$ adsorption to soil colloids compared to the soil where ruzigrass was grown (Fig. 5a and e). Typically, as $\mathrm{NaH}_{2} \mathrm{PO}_{4}$ is titrated to acid soils with variable charged minerals, the reactions are initially highly exothermic, and decrease with each additional $P$ titration, indicative of decreasing ligand exchange of phosphate as the minerals become saturated with $\mathrm{P}$ (Penn and Warren, 2009; Lyngsie et al., 2014; Penn et al., 2014). If the pH is low enough (a)

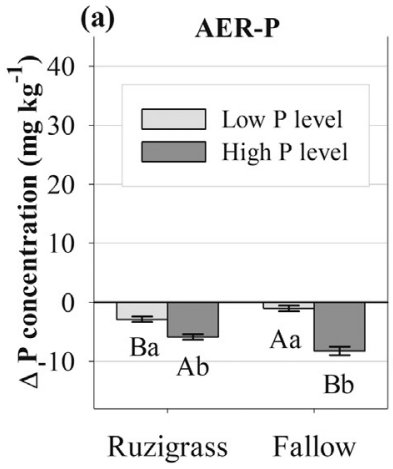

(b)

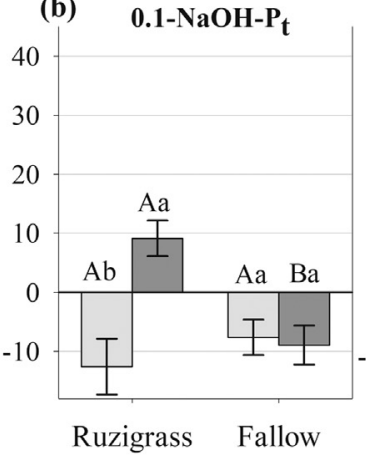

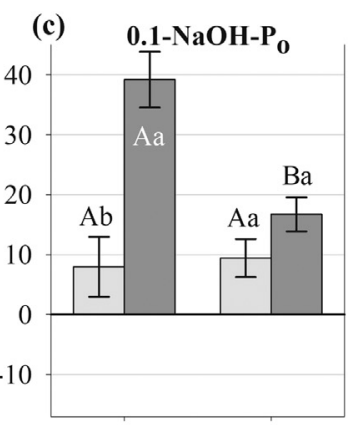

Ruzigrass Fallow
Fig. 6. Change $(\Delta \mathrm{P})$ in soil $\mathrm{P}$ fractions in the rhizosphere soil as compared to initial values, as affected by ruzigrass cultivation and soil P level. (a) Soil P content extracted with AER (anion exchange resin), (b) inorganic + organic P extracted with $0.1 \mathrm{~mol} \mathrm{~L}^{-1} \mathrm{NaOH}$ (0.1-NaOH), and (c) organic P only, as extracted with $0.1-\mathrm{NaOH}$. Means followed by the same letter are not significantly different (Tukey Range Test, $p<0.05$ ). Uppercase letters compare soil cultivated to ruzigrass and soil left in fallow, and lowercase letters compare soil P levels. Error bars represent the standard error. 
(a)

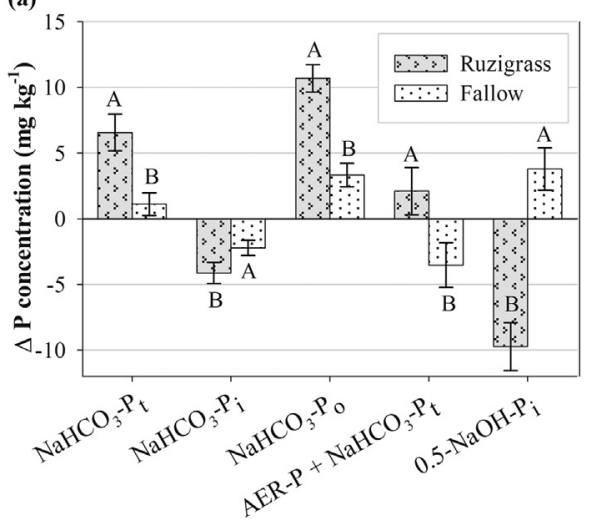

(b)

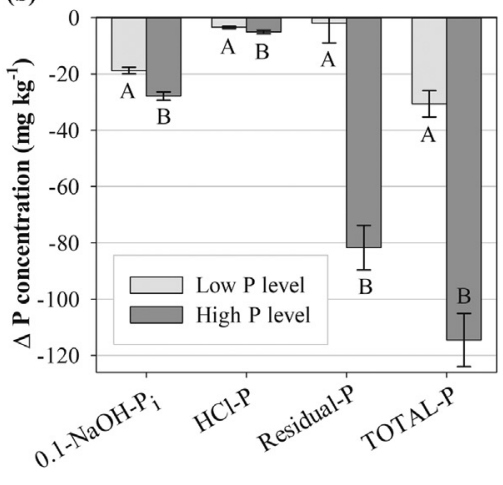

Fig. 7. Change $(\Delta \mathrm{P})$ in soil $\mathrm{P}$ fractions in the rhizosphere soils as compared with initial values, as affected by ruzigrass cultivation and soil P level. (a) inorganic + organic $\mathrm{P}\left(\mathrm{P}_{\mathrm{t}}\right)$ extracted by $\mathrm{NaHCO}_{3}$ inorganic $\mathrm{P}\left(\mathrm{P}_{\mathrm{i}}\right)$ by $\mathrm{NaHCO}_{3}$, organic $\mathrm{P}\left(\mathrm{P}_{\mathrm{o}}\right)$ by $\mathrm{NaHCO}_{3}$, labile fraction content represented by the sum of $\mathrm{P}$ fractions extracted with AER (anion exchange resin) and $\mathrm{NaHCO}_{3}\left(\right.$ AER-P $+\mathrm{NaHCO}_{3}-\mathrm{P}_{\mathrm{t}}$ ), and inorganic $\mathrm{P}$ extracted with $0.5 \mathrm{~mol} \mathrm{~L}^{-1} \mathrm{NaOH}\left(0.5-\mathrm{NaOH}-\mathrm{P}_{\mathrm{i}}\right.$ ). (b) inorganic P extracted with $\mathrm{NaOH} 0.1 \mathrm{~mol} \mathrm{~L}^{-1}\left(0.1-\mathrm{NaOH}-\mathrm{P}_{\mathrm{i}}\right), \mathrm{P}$ extracted with $\mathrm{HCl}$ (HCl-P), Residual-P, and the sum of all $\mathrm{P}$ fractions (Total-P). Different letters indicate significant differences between treatments by Tukey's Range Test $(p<0.05)$, for each soil P fraction. Error bars represent the standard error. and sufficient $\mathrm{P}$ is added, the endotherms will develop, thus indicating precipitation of $\mathrm{Al}$ and $\mathrm{Fe}$ phosphates (Penn and Zhang, 2010; Lyngsie et al., 2014). Soil cultivated with ruzigrass titrated with $\mathrm{NaH}_{2} \mathrm{PO}_{4}$ displayed a high adsorption capacity evidenced by exothermic reactions for all 25 titrations of the low-P soil (Fig. 5a), and a lesser degree of exotherms for the high-P soil. This is likely a consequence of the variable charged minerals being more saturated with $\mathrm{P}$ prior to $\mathrm{P}$ titrations, compared to the low-P soil. Regarding differences in $\mathrm{P}$ titrations between ruzigrass and fallow soils, the higher SOM content in the ruzigrass soil could have increased the ability of $\mathrm{Fe}$ and $\mathrm{Al}$ oxide minerals to adsorb $\mathrm{P}$, and therefore explain why the maximum $\mathrm{P}$ adsorption capacity was higher. In addition, while the fallow soil appeared to be able to release more Ca phosphate to solution with citrate addition than ruzigrass soil, this dissolution could have occurred in the ruzigrass soil as well, except that the newly solubilized $\mathrm{P}$ would likely be immediately adsorbed onto the $\mathrm{Al}$ and $\mathrm{Fe}$ minerals, making it non-available. This is supported by the greater degree of ligand exchange of $\mathrm{P}$ (exotherms) observed for the ruzigrass soil $\mathrm{P}$ titrations, which would also help explain the lower $\mathrm{P}$ uptake by maize in soils previously cultivated with ruzigrass.

Some researchers have observed that SOM and LMWOAs may inhibit $\mathrm{Fe}$ and $\mathrm{Al}$ crystallization and promote the formation of noncrystalline oxides, with a higher surface area and porosity (Singer and Huang, 1990; Violante and Huang, 1992), increasing P adsorption onto Al minerals (Borggaard et al., 1990). According to Borggaard et al. (1990), SOM affects P adsorption indirectly by inhibiting $\mathrm{Al}$ oxide crystallization, resulting in poorly crystalline oxides with high-P adsorption capacity. Hui et al. (2015) also observed an increase in P adsorption to complexes of $\mathrm{Fe}$ and humic acids, mainly at a high $\mathrm{pH}$. Analyzing sandy soils, Debicka et al. (2016) demonstrated an increase in $\mathrm{P}$ desorption after SOM removal. The greater $\mathrm{P}$ adsorption, lesser $\mathrm{P}$ desorption, and the decreased $\mathrm{P}$ uptake by maize in soil previously cropped to ruzigrass vs. fallow may be partly due to the greater SOM contents of the ruzigrass soil, which interacts with the high sesquioxide contents of this soil.

\subsection{Changes in soil $P$ pools with cropping of maize}

A steep decrease in the content of extractable-P fractions is expected in the rhizosphere due to the low concentration of $\mathrm{P}$ in soil solution and the small contribution of mass flow to plant uptake, generating a concentration gradient, a driving force for $\mathrm{P}$ diffusion towards the roots (Hinsinger, 2001). Changes of soil P in the rhizosphere arise from the difference between the demand of the plant and the supply from the soil (Jungk et al., 2002). As expected, analysis of the change in soil P concentrations after maize growth showed that there was $P$ uptake from the AER-P pool in both ruzigrass and fallow soil (Fig. 6). In general, $P_{i}$ extracted by $0.5-\mathrm{NaOH}$ and $\mathrm{NaHCO}_{3}$ was bioavailable, as shown by decreases in these pools after maize (Fig. 7a). Similarly, Residual-P,
HCl-P, and NaOH-P $\mathrm{P}_{\mathrm{i}}$ was either bioavailable or transformed into these pools from other pools with cropping of maize.

It is interesting to note that $\mathrm{P}_{\mathrm{o}}$ extracted with $\mathrm{NaHCO}_{3}$ and 0.1 $\mathrm{NaOH}$ was not bioavailable, while $\mathrm{P}_{\mathrm{i}}$ from these extractants was bioavailable to maize (Figs. 6 and 7). Furthermore, the decrease of those $P_{o}$ pools in maize rhizosphere soil was lower in soil previously cultivated with ruzigrass than fallow. This supports the previous observations that the ruzigrass soil seems to adsorb and desorb P somewhat differently from the fallow soil, for reasons related to higher contents of SOM in the ruzigrass soil. The impact of the SOM on P behavior in this study appears to potentially be due to greater amounts of poorly labile metal phytate pools or phytic acid protected by sesquioxides (affecting desorption), which are extracted with $\mathrm{NaOH}$ and $\mathrm{NaHCO}_{3}$, as well as changes in mineral surfaces due to organic-sesquioxide interactions (affecting adsorption). This would help to explain the lower P uptake by maize growing in soil previously cultivated with ruzigrass as reflected by the lower $\mathrm{P}$ availability due to a lower desorption and higher adsorption of $\mathrm{P}$ in this soil. Therefore, to exploit soil $\mathrm{P}$ recycled by ruzigrass it would be necessary to use plants with high citrate exudation. Further research is required to assess the use of the Resin-P and citrate extraction as an indicator of agronomic available $\mathrm{P}$, and to determine exactly what $\mathrm{P}$ pools are extracted by each one.

\section{Conclusions}

Cultivation of ruzigrass decreased soil-P bioavailability as compared with soil that was fallowed, even though the presence of ruzigrass increased pearl resin-extractable P. Conversely, soil P extraction with citrate, an organic acid often released by plant roots to improve bioavailability, was better related to maize $P$ uptake. Isothermal titration calorimetry was a useful tool and indicator for assessing soil $\mathrm{P}$ availability. In general, ruzigrass soil exhibited a greater potential for ligand exchange of citrate and $\mathrm{P}$. The lower $\mathrm{P}$ desorption and higher $\mathrm{P}$ adsorption observed through calorimetry, complementary citrate extraction, and soil rhizosphere $\mathrm{P}$ fractionation, suggested that soil previously cropped with ruzigrass may have developed less soluble $\mathrm{Fe}$ and Alphytate compounds, and potentially more effective Fe and Al adsorption sites, due to interactions with the higher SOM contents. Fallow soil may have been able to release Ca phosphate to solution more readily, with less re-adsorption of the $\mathrm{P}$ onto the $\mathrm{Fe}$ and $\mathrm{Al}$ oxyhydroxide minerals. In summary, ruzigrass cultivation resulted in P bound to SOM, possibly as phytates, unavailable to plants, but also protected against loss to the environment.

\section{Acknowledgements}

This research was supported by São Paulo Research Foundation (FAPESP) grant \#2012/18509-4. 


\section{Appendix A. Supplementary data}

Supplementary data to this article can be found online at https:// doi.org/10.1016/j.geoderma.2017.10.003.

\section{References}

Almeida, D.S., 2014. Disponibilidade de fósforo em solo cultivado com braquiária em rotação com soja. São Paulo State University (Dissertation Thesis, 80 pp.)

Almeida, D.S., Rosolem, C.A., 2016. Ruzigrass grown in rotation with soybean increases soil labile phosphorus. Agron. J. 108, 1-9. http://dx.doi.org/10.2134/agronj2015. 0478.

Almeida, J.A., Torrent, J., Barrón, V., 2003. Cor de solo, formas do fósforo e adsorção de fosfatos em Latossolos desenvolvidos de basalto do extremo-sul do Brasil. Rev. Bras. Ciênc. Solo 27, 985-1002. http://dx.doi.org/10.1590/S0100-06832003000600003.

Anghinoni, I., Baligar, V.C., Wright, R.J., 1996. Phosphorus sorption isotherm characteristics and availability parameters of Appalachian acidic soils. Commun. Soil Sci. Plant Anal. 27, 2033-2048. http://dx.doi.org/10.1080/00103629609369686.

Berg, A.S., Joern, B.C., 2006. Sorption dynamics of organic and inorganic phosphorus compounds in soil. J. Environ. Qual. 35, 1855-1862. http://dx.doi.org/10.2134/ jeq2005.0420.

Berggren, D., Mulder, J., 1995. The role of organic matter in controlling aluminum solubility in acidic mineral soil horizons. Geochim. Cosmochim. Acta 59, 4167-4180. http://dx.doi.org/10.1016/0016-7037(95)94443-J.

Boddey, R.M., Rao, I.M., Thomas, R.J., 1996. Nutrient cycling and environmental impact of Brachiaria pastures. In: Miles, J., Maass, B.L., Do Valle, C.B. (Eds.), Brachiaria: Biology, Agronomy and Improvement. CIAT/EMBRAPA, Cali/Brasília, pp. 72-86.

Borggaard, O.K., Jdrgensen, S.S., Moberg, J.P., Raben-Lange, B., 1990. Influence of organic matter on phosphate adsorption by aluminium and iron oxides in sandy soils. J. Soil Sci. 41, 443-449. http://dx.doi.org/10.1111/j.1365-2389.1990.tb00078.x.

Campos, M., Antonangelo, J.A., Alleoni, L.R.F., 2016. Phosphorus sorption index in humid tropical soils. Soil Tillage Res. 156, 110-118. http://dx.doi.org/10.1016/j. still.2015.09.020.

Condron, L.M., Goh, K.M., 1989. Effects of long-term phosphatic fertilizer applications on amounts and forms of phosphorus in soils under irrigated pasture in New Zealand. J. Soil Sci. 40, 383-395. http://dx.doi.org/10.1111/j.1365-2389.1989.tb01282.x.

Cross, A.F., Schlesinger, W.H., 1995. A literature review and evaluation of the Hedley fractionation: applications to the biogeochemical cycle of soil phosphorus in natural ecosystems. Geoderma 64, 197-214. http://dx.doi.org/10.1016/0016-7061(94) 00023-4.

Dao, T.H., 2003. Polyvalent cation effects on-inositol hexa dihydrogenphosphate enzymatic dephosphorylation in dairy wastewater. J. Environ. Qual. 32, 694-701. http:// dx.doi.org/10.2134/jeq2003.6940.

Dao, T.H., 2004. Organic ligand effects on enzymatic dephosphorylation of-inositol hexa dihydrogenphosphate in dairy wastewater. J. Environ. Qual. 33, 349-357. http://dx. doi.org/10.2134/jeq2004.3490.

Debicka, M., Kocowicz, A., Weber, J., Jamroz, E., 2016. Organic matter effects on phosphorus sorption in sandy soils. Arch. Agron. Soil Sci. 62, 840-855. http://dx.doi. org $/ 10.1080 / 03650340.2015 .1083981$.

Dick, W.A., Tabatabai, M.A., 1977. Determination of orthophosphate in aqueous solutions containing labile organic and inorganic phosphorus compounds. J. Environ. Qual. 6, 82-85. http://dx.doi.org/10.2134/jeq1977.00472425000600010018x.

Earl, K.D., Syers, J.K., McLaughlin, J.R., 1979. Origin of the effects of citrate, tartrate, and acetate on phosphate sorption by soils and synthetic gels. Soil Sci. Soc. Am. J. 43, 674-678. http://dx.doi.org/10.2136/sssaj1979.03615995004300040009x.

Fox, T.R., Comerford, N.B., McFee, W.W., 1990. Phosphorus and aluminum release from a spodic horizon mediated by organic acids. Soil Sci. Soc. Am. J. 54, 1763-1767. http://dx.doi.org/10.2136/sssaj1990.03615995005400060043x.

Geelhoed, J.S., Hiemstra, T., Van Riemsdijk, W.H., 1998. Competitive interaction between phosphate and citrate on goethite. Environ. Sci. Technol. 32, 2119-2123. http://dx.doi.org/10.1021/es970908y.

Giaveno, C., Celi, L., Richardson, A.E., Simpson, R.J., Barberis, E., 2010. Interaction of phytases with minerals and availability of substrate affect the hydrolysis of inosito phosphates. Soil Biol. Biochem. 42, 491-498. http://dx.doi.org/10.1016/j.soilbio. 2009.12.002.

He, Z., Honeycutt, C.W., Zhang, T., Bertsch, P.M., 2006. Preparation and FT-IR characterization of metal phytate compounds. J. Environ. Qual. 35, 1319-1328. http:// dx.doi.org/10.2134/jeq2006.0008.

Hedley, M.J., Stewart, J.W.B., Chauhan, B.S., 1982. Changes in inorganic and organic soil phosphorus fractions induced by cultivation practices and by laboratory incubations. Soil Sci. Soc. Am. J. 46, 970-976. http://dx.doi.org/10.2136/sssaj1982. $03615995004600050017 x$

Hinsinger, P., 2001. Bioavailability of soil inorganic P in the rhizosphere as affected by root-induced chemical changes: a review. Plant Soil 237, 173-195. http://dx.doi.org/ 10.1023/A:1013351617532.

Hui, W., Jun, Z., Qing-Ling, F., Xiong, J.-W., Can, H., Hong-Qing, H., Violante, A., 2015.
Adsorption of phosphate onto ferrihydrite and ferrihydrite-humic acid complexes. Pedosphere 25, 405-414.

Jones, D.L., Brassington, D.S., 1998. Sorption of organic acids in acid soils and its implications in the rhizosphere. Eur. J. Soil Sci. 49, 447-455. http://dx.doi.org/10. 1046/j.1365-2389.1998.4930447.x.

Jones, D.L., Darrah, P.R., 1994. Role of root derived organic acids in the mobilization of nutrients from the rhizosphere. Plant Soil 166, 247-257. http://dx.doi.org/10.1007/ BF00008338.

Jones, D.L., Kochian, L.V., 1996. Aluminium-organic acid interactions in acid soils. Plant Soil 182, 221-228. http://dx.doi.org/10.1007/BF00029053.

Jungk, A.O., Waisel, Y., Eshel, A., Kafkafi, U., 2002. Dynamics of nutrient movement at the soil-root interface. In: Kafkafi, U., Waisel, Y., Eshel, A. (Eds.), Plant Roots: The Hidden Half. Marcel Dekker, New York, pp. 587-616.

Lyngsie, G., Penn, C.J., Hansen, H.C.B., Borggaard, O.K., 2014. Phosphate sorption by three potential filter materials as assessed by isothermal titration calorimetry. J. Environ. Manag. 143, 26-33. http://dx.doi.org/10.1016/j.jenvman.2014.04.010.

Malavolta, E., Vitti, G.C., Oliveira, A.S., 1997. Avaliação do estado nutricional das plantas: princípios e aplicações. Potafós, Piracicaba.

Merlin, A., He, Z.L., Rosolem, C.A., 2013. Ruzigrass affecting soil-phosphorus availability Pesq. Agrop. Brasileira 48, 1583-1588. http://dx.doi.org/10.1590/s0100204x2013001200007.

Merlin, A., Rosolem, C.A., He, Z.L., 2015. Non-labile phosphorus acquisition by Brachiaria. J. Plant Nutr. 39, 1319-1327. http://dx.doi.org/10.1080/01904167. 2015.1109117.

Miltenburg, J.C., Golterman, H.L., 1997. The energy of the adsorption of o-phosphate onto ferric hydroxide. Hydrobiologia 364, 93-97. http://dx.doi.org/10.1023/ A:1003107907214.

Murphy, J., Riley, J.P., 1962. A modified single solution method for the determination of phosphate in natural waters. Anal. Chim. Acta 27, 31-36. http://dx.doi.org/10.1016/ S0003-2670(00)88444-5.

Olibone, D., Rosolem, C.A., 2010. Phosphate fertilization and phosphorus forms in an Oxisol under no-till. Sci. Agric. 67, 465-471. http://dx.doi.org/10.1590/S010390162010000400014

Pavinato, P.S., Rosolem, C.A., 2008. Disponibilidade de nutrientes no solo: decomposição e liberação de compostos orgânicos de resíduos vegetais. Rev. Bras. Ciênc. Solo 32, 911-920. http://dx.doi.org/10.1590/S0100-06832008000300001.

Penn, C.J., Warren, J.G., 2009. Investigating phosphorus sorption onto kaolinite using isothermal titration calorimetry. Soil Sci. Soc. Am. J. 73, 560. http://dx.doi.org/10 2136/sssaj2008.0198.

Penn, C.J., Zhang, H., 2010. Isothermal titration calorimetry as an indicator of phosphorus sorption behavior. Soil Sci. Soc. Am. J. 74, 502. http://dx.doi.org/10.2136/ sssaj2009.0199.

Penn, C., Heeren, D., Fox, G., Kumar, A., 2014. Application of isothermal calorimetry to phosphorus sorption onto soils in a flow-through system. Soil Sci. Soc. Am. J. 78, 147. http://dx.doi.org/10.2136/sssaj2013.06.0239.

Raij, B., Quaggio, J.A., Da Silva, N.M., 1986. Extraction of phosphorus, potassium, calcium, and magnesium from soils by an ion-exchange resin procedure. Commun. Soil Sci. Plant Anal. 17, 547-566. http://dx.doi.org/10.1080/00103628609367733.

Raij, B., Andrade, J.C., Cantarella, H., Quaggio, J.A., 2001. Análise química para avaliação da fertilidade de solos tropicais. Instituto Agronômico, Campinas.

Rhue, R.D., Appel, C., Kabengi, N., 2002. Measuring surface chemical properties of soil using flow calorimetry. Soil Sci. 167, 782-790. http://dx.doi.org/10.1097/01.ss. 0000043036.84859 .98

Sharpley, A.N., 1995. Soil phosphorus dynamics: agronomic and environmental impacts. Ecol. Eng. 5, 261-279. http://dx.doi.org/10.1016/0925-8574(95)00027-5.

Singer, A., Huang, P.M., 1990. Effects of humic acid on the crystallization of aluminum hydroxides. Clay Clay Miner. 38, 47-52. http://dx.doi.org/10.1346/CCMN.1990. 0380106.

Soil Survey Staff, 2014. Keys to Soil Taxonomy Keys to Soil Taxonomy. USDA-Natural Resources Conservation Service.

Sparks, D.L., 2003. Environmental Soil Chemistry. Academic Press, San Diego.

Veith, J.A., Sposito, G., 1977. On the use of the Langmuir equation in the interpretation of "adsorption" phenomena. Soil Sci. Soc. Am. J. 41, 697-702. http://dx.doi.org/10. 2136/sssaj1977.03615995004100040015x.

Violante, A., Huang, P.M., 1992. Effect of tartaric acid and $\mathrm{pH}$ on the nature and phy sicochemical properties of short-range ordered aluminum precipitation products. Clay Clay Miner. 40, 462-469. http://dx.doi.org/10.1346/CCMN.1992.0400411.

Warren, J.G., Penn, C.J., McGrath, J.M., Sistani, K., 2008. The impact of aluminum addition on organic P transformations in poultry litter and litter-amended soil. J. Environ. Qual. 37, 469-476. http://dx.doi.org/10.2134/jeq2007.0239.

Wenzl, P., Patino, G.M., Chaves, A.L., Mayer, J.E., Rao, I.M., 2001. The high level of aluminum resistance in signalgrass is not associated with known mechanisms of ex ternal aluminum detoxification in root apices. Plant Physiol. 125, 1473-1484. http:// dx.doi.org/10.1104/pp.125.3.1473.

Wu, C., Dobrogowska, C., Zhang, X., Hepler, L.G., 1997. Calorimetric investigations of $\mathrm{Al}^{3+}$ (aq), $\mathrm{Al}(\mathrm{OH}) 4-(\mathrm{aq})$, and aluminium-citrate complexes at 298.15 K. Can. J. Chem. 75, 1110-1113. http://dx.doi.org/10.1139/v97-132. 